\title{
A PROPOSED METHOD FOR EXAMINING BLEACHED FLOUR.
}

\author{
BY Roscoz H, SHaw.
}

Received March I0, I906.

THE natural or "aging" process for bleaching flour is being rapidly superseded in western flouring mills by artificial methods. This fact has led to complaints from bakers who, having become accustomed to judge the quality of a flour to some extent by its color, are no longer able to distinguish the different grades as they previously did, since a poor grade may be bleached artificially to approach in whiteness a much higher grade.

Although there are several processes for artificial bleaching on the market, as far as the writer's knowledge goes the higher oxides of nitrogen play a part in each of them.

In searching for a chemical method for recognizing artificially bleached flour, the ground was taken that some nitro body might exist either as residual nitric oxide or as some nitro starch compound in flour so bleached that would not be present in natural flour, and if so its presence would serve as an identification.

The use of the well-known test for nitrates or certain other strong oxidizing agents, diphenylamine, was suggested by Dr. S. Avery of this university, who has used it successfully in detecting nitrates in organic matter.

In all, eight samples of flour were examined. Three of these were reported to have been bleached by the electric flaming discharge process, one by the electrochemical process, one by the straight chemical process, and one by the exothermic process. The other two were unbleached.

The method of procedure was as follows: About $\mathrm{I} \mathrm{kg}$. of flour was boiled for four hours with 95 per cent. alcohol in a balloon flask provided with a reflux condenser. After cooling, the liquid part was removed by filtering and the flour washed once with alcohol. The united extract and washings were evaporated nearly to dryness and this residue extracted with a mixture of equal parts of alcohol and ether. By allowing the first extract to cool before filtering, the most of the fat was removed and the alcohol-soluble proteids were not redissolved in the alcohol-ether extraction. The last extract was filtered and evaporated to a syrup in a 4 -inch porcelain evaporating dish. The syrupy mass 
was caused to spread itself in a film over the inside of the dish and a drop of a sulphuric acid solution of diphenylamine allowed to trail over the film.

The solution of diphenylamine was made by dissolving it in concentrated sulphuric acid and then diluting with water almost to the point of precipitation.

In each case where the flour was reported to have been artificially bleached the drop left a blue path, while no coloration was perceptible in the cases of the unbleached flour. In some instances the blue was not so sharp as might be wished for but was in all cases distinguishable.

A flour bleached by a process using ozone alone as a bleaching agent would probably not respond to the diphenylamine test. Such a process, however, is not used in the West to the writer's knowledge. It is also possible but highly improbable that a flour might be found which, fresh from the wheat, would yield the blue color when tested. To decide these points a much larger number of samples will be examined.

THE UNIVERSITy OF NEBRASKA,

LINCOLN, NEBRASKA.

[CONTRIBUTION FROM THE Division OF FoOds, BUREAU OF Chemistry, United STATES Department of Agriculture.

SEAT BY H. W. WILEY.]

\section{GROWTH AND RIPENING OF PERSIMMONS. ${ }^{1}$}

BX W. D. BIgeLow, H. C. Gore AND B. I. Howard.

Received April 3, Igo6.

THE present work is a part of the systematic study of the ripening of fruits which we have undertaken, and regarding which two reports have already been made. ${ }^{2}$ It has been found impossible to make as complete a study of the composition of a given fruit at various stages of its growth as is desirable, owing to the fact that some of the important constituents are present in many fruits in such a small amount that the limits of error of their estimation effectually preclude the possibility of determining the rate of their increase and decrease.

${ }^{1}$ Presented at the New Orleans Meeting of the American Chemical Society, December 30, 1905.

${ }^{2}$ U. S. Dept. Agr., Bur. Chem., Bull. 94, Studies on Apples, and U. S. Dept. Agri., Bur. Chem., Bull. 97, Studies on Peaches. 